\title{
Perspectives for School: Maker Approach, Educational Technologies and Laboratory Approach, New Learning Spaces
}

\author{
Margherita Di Stasio $\mathbb{D}$ and Beatrice Miotti $\mathbb{C}$
}

\begin{abstract}
Technology has become an ordinary, constituent element of today's world. Therefore, digital skills are not only important, but ultimately necessary for all. This makes it mandatory for school and educational research to construct learning paths with an educational rather than a training approach to technology. The purpose of school is not to prepare students to be users of an instrument, but, above all, to kindle in them an awareness of the process that can stem from creation. This chapter aims to highlight some of the topics emerging from international discussion on school and learning methodologies. First, one of the interesting topics is the Maker approach and productive partnerships with schools, including in relation to the original concept of craftsmanship, forerunner of the term "maker". Second, educational robotics and the laboratory as tools for improving deep learning, abstract thinking and problemsolving skills, without forgetting to look at the ethical and social issues of introducing robots into our lives. Third, learning spaces and new school buildings have to meet the changing paradigms of learning approaches. There are countless opportunities for improving digital skills and methodological approaches. Teachers should be aware of all these possibilities and be ready to get training and apply them in their everyday lessons.
\end{abstract}

Keywords Makers • Educational robotics - Learning spaces $\cdot$ Constructivism • Teacher training

\footnotetext{
Although this chapter has been jointly conceived, Margherita Di Stasio wrote Section 1, 2 and 4; Betrice Miotti developed Section 3.

M. Di Stasio (凶) • B. Miotti

Istituto Nazionale Documentazione Innovazione Ricerca Educativa (Indire), via M. Buonarroti 10, 50122 Florence, Italy

e-mail: m.distasio@indire.it

B. Miotti

e-mail: b.miotti@indire.it
} 


\section{Introduction}

The evolution of technology is not limited to itself: as the history of science and technology—sub specie philosophica-have taught us, periods of true revolution involve technological, cultural and social factors [1].

It is clear that, in recent years, our world has undergone a never-before-seen technological acceleration [2]. Our reality is marked by highly pervasive technologies that have us facing dimensions like the infosphere [3] and the internet of things [4] as parts of a world in which our life is characterized as onlife [5]. One emerging and characteristic element of this world is so-called "digital craftsmanship", Makers, that is finding its own dimension in society and in the economy.

An educational and non-training approach to technology aims not only to produce users of instruments, but, above all, to kindle in them an awareness of the process that can stem from creation.

Education and pedagogy should work actively to make students, children and young people aware of the world in which they live and be able to be active in it.

Digital craftsmanship is also finding a distinctive role in education [6], in a perspective in which fab labs are "democratizing the maker movement for students" $[7]$.

\section{Maker Dimension}

The craft dimension of "doing" is what gives meaning and perspective for understanding a digital world and society. That is not a contradiction in terms. This is why.

The spread of personal computers and networks has led to the dissemination of technology in everyday personal and work life. Web 2.0 and the emergence of social networking have led to the creation of participatory cultures [8] and the development of media education.

Even if the instrument created by Bernard Lee ${ }^{1}$ for a community of select scientists seemed to be available to everyone, the relationship between hardware and software and the Logic behind technology has remained the prerogative of a narrow group of specialists.

The desire to share what is produced by man with technology, and to have technology serving the needs of humans distinguishes the open source and free software ${ }^{2}$ community. Hacker ethic comes from, develops and is spread, both in the literature and indeed, by people like Himanen [9] and Torvald [10], who gave his name to the Linux operating system.

The hacker movement and the maker movement share this desire to make technology accessible and understandable for more people.

\footnotetext{
${ }^{1}$ The first website can be browsed at http://info.cern.ch/.

${ }^{2}$ On this topic see https://www.fsf.org/ and https://www.fsf.org/.
} 
As stated [7], the maker movement draws inspiration from the hackerspace for improvement; it also presents its activities as being accessible to everybody, not only to people who are prepared and specialized.

The very first statement of the Maker Movement Manifesto claims that "making is fundamental to what it means to be human. We must make, create, and express ourselves to feel whole. There is something unique about making physical things. Things we make are like little pieces of us and seem to embody portions of our soul" [11]. The value of experience emerges in affective terms. On one hand, it restores the human element to the handling of technology. On the other, it is related to the learning by doing tradition of Freinet and Papert.

Some making dimensions are meaningful in the school context. The addition of makerspaces can be of great significance when it comes to redesigning teaching and learning spaces. Making is a structured and complex process and may require active and real collaboration in which the co-construction of knowledge is encouraged. It leads to a deeper understanding of the mechanisms that underlie interaction with technology, opening up opportunities for active media education. It also helps the development of design and reflection processes that can be modelized and applied in different social and educational contexts.

\section{Trends and Perspectives}

"School has to change" is the common thread that runs through all the contributions in this track. School and all of the elements that make it up-educational system, learning approaches, building design, organization of time-are centuries old.

It is rooted in the lecture-based teaching model, which is no longer suitable [12, 12] because the youth of today "are connected to everything, and they have a sense of urgency because of climate change at our doorstep, the dying oceans, and social issues such as systemic racism coming to a head. All of this is happening in front of their eyes. This is a generation that feels the urgency of changing the world." [14].

And so, the most important question research tries to answer is: "How and what do we want those children and teens to learn, so that in the future they can become more like the inspiring young people mentioned above? [Cf. Boyan Slat, Greta Thunberg and the Parkland survivors]" [14].

It is clear how school should change. Instead of the lecture-based school model a "[...] well-thought-out laboratory approach helps children to learn, plan, communicate and collaborate, act independently and responsibly, solve problems, identify connections and interpret information." [15] Moreover, "The education system should not be designed for a standard (and its related standardized tests), but should bring out the divergent thinking and creativity of each student." [16]. Technology and educational robotics can be used to improve the learning process: "pedagogical factors that make technology-enhanced learning successful: learning motivation, cognitive development, cognitive load, and knowledge development in the discourse of technology-enhanced learning" [17] and "educational use of robots stimulates 
productive, creative and divergent thinking and is useful for understanding how students learn." [15].

Thus the maker approach can be seen as a virtuous example and a model to imitate, because "contemporary craftsmen are those who know how to use digital technologies with mastery, and consider quality, innovation and social cooperation to be fundamental values in their work" [18], "if you redesigned schools from scratch, they would probably look like a well-functioning makerspace" [14]. However, in order for this collaboration between schools and the maker approach to be worthwhile, a School Makerspace manifesto is needed "Schools and makers are two very broad, diverse and elaborate entities. Yet, as long as they can find common ground, they can create a lab where they can work together but also separately, according to their individual needs." [13].

But school cannot change if teachers are not ready to reinvent the way they teach, by moving from a face-to-face lesson model to a variety of teaching methods and learner-centered strategies, including with technological support. So, in the new school model, it is extremely important to "strengthen the professionalism of teachers, through research-training and participatory action research," [15] and to ensure "teachers have the appropriate digital competence to use technology, which in turn affects the extent to which the opportunities created by technology will be used in the learning process" [17].

Looking at the use of robotics or artificial intelligence at school but also in everyday life, we cannot help but consider "the ethical, legal and societal issues (ELS) inherent to that field" that we are going face. Roboethics is a new science that studies "the protection of privacy, the defense of human dignity, distributive justice and the dignity of work" [19] in relation to ELS issues.

\subsection{Experiences and Points of View}

The urgent need for change in the school system clearly emerges in [14], which puts forward a number of interesting points of view for building an education system from scratch. The school model has been the same for centuries and only recently have new methodologies been put forward; however the renewal process is too slow for the needs of young people today. Blikstein states that schools should do more than teach arithmetic and other subjects; it should also equip young people to deal with the big issues of society and the world. Blikstein also argues that the best approach to learning can be found in the makerspace model, where project-based learning, learning that is meaningful to kids, student agency, inclusive environments, new types of skills, using technology as an expressive material are already happening.

According to [18] the maker approach stems from the concept of craftsmanship, although in a broader sense that is not only related to manual labor, but also to intellectual activities, such as art, mastery, and computer programming. Ranieri states that contemporary craftspeople are experts at using technology; they openly share information, promote the circulation of ideas, and are candid about problems and how 
to solve them. This maker approach should also be applied in educational settings, by bending technology to students' needs and promoting new learning paths.

The same ideas are presented by Aprile in [16]. As a teacher, Aprile agrees with Blikstein [14] that the current vision of school is outdated, especially given the challenges of a globalized, hyperdynamic world. Aprile compares schools to a factory production line where the pedagogical models, the buildings and the way time is organized limit the ability to take account of every student's specific skills and awareness. The author proposes the term "edumaker" to represent a teacher-maker in education with a proactive attitude and a desire to get involved personally in the learning process (analytical thinking, creativity, problem-solving, collaborative working).

Setting up a makerspace in a school is a very challenging process, but it demands a vision that is shared by both the school and the maker to evaluate opportunities and establish terms that are beneficial to both. In [13], the author proposes a "Makerspace Manifesto" which schools and makers can use immediately to organize a collaboration. The arrangement ensures benefits for both partners: schools provide the furniture, and makers can use it and the makerspace outside of school hours. Makers can train teachers in laboratory practices, to empower them to offer maker activities during curricular lessons.

In order to get to a place where it can distance itself from the face-to-face lesson model and embrace a variety of teaching methods and learner-centered strategies, including with technological support, school needs to re-think its very foundations. In [12], Borri refers to the " $1+4$ Learning Spaces for a New Generation of Schools" framework, whereby learning spaces should be designed for a range of different activities, featuring task-oriented zones fitted with flexible furniture and a variety of educational materials and tools. Each $1+4$ space is suitable for a different type of student learning activity, whether it is individual work or teacher-supervised: Group Space, Exploration Lab, Agora, Individual Area, Informal Area.

The laboratory is also central to the research reported in [15]. Here it is an educational space and a privileged setting, where research and training can take place and new knowledge can be developed. Zecca describes the results of research in primary school students where robots are used to develop research skills, such as observation, explanatory hypothesis formulation, hypothesis testing, and review of hypotheses in light of the results observed, using a dialogical approach. In this research, children did not have to program robots but rather to explain the robot's behavior, in order to develop abstract thinking and problem-solving skills.

In [17], Daniela suggests we should reflect on technology-enhanced learning and the place and role of technology in education. The author identifies five different objectives for learning technology in educational models: learning technology that supports the knowledge acquisition process; learning technology that provides access to knowledge; learning the principles of developing new technologies and finding new creative solutions; the interrelationships of learning motivation and learning achievements; evaluating learning achievements.

The use of technology, especially robotics, in educational settings and for social purposes has led the research community to question its impact on ethical, legal and social aspects. In [19] Operto describes robotics as a very powerful tool for studying 
and increasing our knowledge, not only of the universe around us-space, oceans, our bodies-but also our brains/minds. On the other hand, robotics is going to be pervasive in the world, and ethical issues need to be addressed so we can define (the extent and limits of) human responsibility and machine autonomy, in cases of damage caused by a learning robot. Roboethics, the field that studies ELS issues, is going to have an impact on the design, programming, shape and use of robots.

\section{Conclusions}

The information society is a neo-manufacturing society, in which data, information and digital processes are raw materials. We need to teach the languages of digital design; in other words, not only Italian and English, but also mathematics, statistics, industrial design, computer science, law, the language of science, architecture, art, music, and dead languages. We need to be able to read and write digitally so we can be critical and informed creators and caretakers of the world around us. ${ }^{3}$

We can refer to these statements made by Floridi a few years ago in an Italian newspaper, and use them as an expression of our expectations and hopes for a school that creates citizens of the world and not consumers.

The practice of a maker education can contribute to this aim in two ways: first, by providing a different technological awareness; second, but no less important, by setting out a methodological approach that allows the adoption of new and different attitudes to fundamental issues, such as equity, gender issues sustainability and many more.

\section{References}

1. Rossi, P.: La scienza e la filosofia dei moderni: aspetti della rivoluzione scientifica. Bollati Boringhieri (1989)

2. Floridi, L.: Philosophy and Computing: An Introduction. Routledge, London and New York (1999)

3. Floridi, L.: The Fourth Revolution: How the Infosphere is Reshaping Human Reality. OUP, Oxford (2014)

4. New Media Consortium, Horizon Report: 2017 Higher Education Edition. https://www.unmc. edu/elearning/_documents/NMC_HorizonReport_2017.pdf (2017)

5. Floridi, L.: The Onlife Manifesto: Being Human in a Hyperconnected Era, p. 264. Springer Nature (2015)

6. Schön, S., Ebner, M., Kumar, S.: «The Maker Movement Implications from Modern Fabrication, New Digital Gadgets, and Hacking for Creative Learning and Teaching». eLearning Papers Special Edition, 86-100 (2014)

7. Blikstein, P.: Maker movement in education: History and prospects. Handbook Technol. Educ. pp. 419-437 (2018)

\footnotetext{
${ }^{3}$ https://www.ilsole24ore.com/art/il-design-futuro-sara-gruppo--riscoperta-sapere-umanistico-faevolvere-1-uomo-tecnologico-AEw2R0GF.
} 
8. Jenkins, H.: Confronting the Challenges of Participatory Culture: Media Education for the 21st Century, p. 145. The MIT Press (2009)

9. Himanen, P.: The Hacker Ethic. Random House (2001)

10. Torvalds, L., Diamond, D.: Just for Fun: The Story of an Accidental Revolutionary. Harper Audio (2001)

11. Hatch, M.: The Maker Movement Manifesto, p. 11. McGraw-Hill Education (2013)

12. Borri, S.: From the classroom to the learning environment. In: Scaradozzi, D., Guasti, L., Di Stasio, Miotti, B., Monteriù, A., Blikstein, P. (eds.) Makers at School, Educational Robotics and Innovative Learning Environments-FabLearn Italy 2019. Springer (in press)

13. Nulli, G.: School makerspace manifesto. In: Scaradozzi, D., Guasti, L., Di Stasio, Miotti, B., Monteriù, A., Blikstein, P. (eds.) Makers at School, Educational Robotics and Innovative Learning Environments-FabLearn Italy 2019. Springer (in press)

14. Blikstein, P.: If we could start from scratch, what would schools look like in the 21 st century? Rethinking Schools as a Locus for Social Change. In: Scaradozzi, D., Guasti, L., Di Stasio, Miotti, B., Monteriù, A., Blikstein, P. (eds.) Makers at School, Educational Robotics and Innovative Learning Environments-FabLearn Italy 2019. Springer (in press)

15. Zecca, L.: The game of thinking. Interactions between children and robots in educational environments. In: Scaradozzi, D., Guasti, L., Di Stasio, Miotti, B., Monteriù, A., Blikstein, P. (eds.) Makers at School, Educational Robotics and Innovative Learning EnvironmentsFabLearn Italy 2019. Springer (in press)

16. Aprile, D.: Makers in education: teaching is a hacking stuff. In: Scaradozzi, D., Guasti, L., Di Stasio, Miotti, B., Monteriù, A., Blikstein, P. (eds.) Makers at School, Educational Robotics and Innovative Learning Environments-FabLearn Italy 2019. Springer (in press)

17. Daniela, L.: Pedagogical considerations for technology-enhanced learning. In: Scaradozzi, D., Guasti, L., Di Stasio, Miotti, B., Monteriù, A., Blikstein, P. (eds.) Makers at School, Educational Robotics and Innovative Learning Environments-FabLearn Italy 2019. Springer (in press)

18. Ranieri, M.: Making to learn. The pedagogical implications of making in a digital binary world. In: Scaradozzi, D., Guasti, L., Di Stasio, Miotti, B., Monteriù, A., Blikstein, P. (eds.) Makers at School, Educational Robotics and Innovative Learning Environments-FabLearn Italy 2019. Springer (in press)

19. Operto, F.: Elements of roboethics. In: Scaradozzi, D., Guasti, L., Di Stasio, Miotti, B., Monteriù, A., Blikstein, P. (eds.) Makers at School, Educational Robotics and Innovative Learning Environments-FabLearn Italy 2019. Springer (in press)

Open Access This chapter is licensed under the terms of the Creative Commons Attribution 4.0 International License (http://creativecommons.org/licenses/by/4.0/), which permits use, sharing, adaptation, distribution and reproduction in any medium or format, as long as you give appropriate credit to the original author(s) and the source, provide a link to the Creative Commons license and indicate if changes were made.

The images or other third party material in this chapter are included in the chapter's Creative Commons license, unless indicated otherwise in a credit line to the material. If material is not included in the chapter's Creative Commons license and your intended use is not permitted by statutory regulation or exceeds the permitted use, you will need to obtain permission directly from the copyright holder.

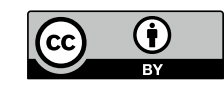

